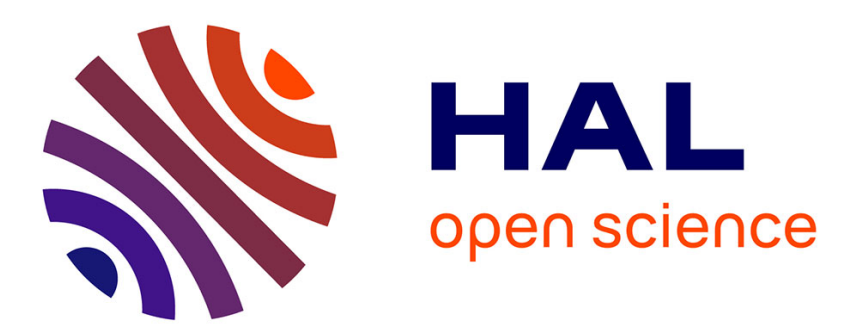

\title{
Costs and benefits of recycling PVC contaminated with the legacy hazardous plasticizer DEHP
}

\author{
Jean-Marc Brignon
}

\section{To cite this version:}

Jean-Marc Brignon. Costs and benefits of recycling PVC contaminated with the legacy hazardous plasticizer DEHP. Waste Management and Research, 2021, pp.0734242X2110067. $10.1177 / 0734242 \mathrm{X} 211006755$. ineris- 03249483

HAL Id: ineris-03249483

https://hal-ineris.archives-ouvertes.fr/ineris-03249483

Submitted on 4 Jun 2021

HAL is a multi-disciplinary open access archive for the deposit and dissemination of scientific research documents, whether they are published or not. The documents may come from teaching and research institutions in France or abroad, or from public or private research centers.
L'archive ouverte pluridisciplinaire HAL, est destinée au dépôt et à la diffusion de documents scientifiques de niveau recherche, publiés ou non, émanant des établissements d'enseignement et de recherche français ou étrangers, des laboratoires publics ou privés. 


\title{
Costs and benefits of recycling PVC contaminated with the legacy hazardous plasticizer DEHP.
}

\author{
Journal: Waste Management \& Research: The Journal for a Sustainable Circular \\ Economy \\ Complete List of Authors: BRIGNON, Jean-Marc; INERIS, \\ Keywords: \\ Recycling, Environmental Impacts, Chemicals, External cost, PVC, \\ Material Flow Analysis
}

Reusing materials is an attractive option for circular economy and can also reduce emissions of greenhouse gases and pollutants. However, recycling raises questions regarding the potential risks to human health or the environment when hazardous legacy chemical additives of materials are also recycled, instead of the recent and less hazardous additives of virgin materials.

To address this trade-off, this study developed a model to calculate the total external cost of material supply, considering the health and environmental impacts of all industrial steps (virgin material production, incineration, recycling), and the health effects of recycling chemicals

Abstract: present in the material. The model is coupling Material flow analysis, Life-Cycle Analysis, and environmental economics to compare different recycling policies. It is applied for illustrative purposes to soft PVC and DEHP in France. Results show that recycling of materials is in the longterm positive despite the prolongation of the presence of hazardous additives in materials. The time when the recurring environmental benefits of recycling offset the negative impacts on human health of recycling the additives is very sensitive to the health impact of additives. The approach can improve harmonisation between recycling and circular economy policies, and as a framework to confirm the relevance and to size treatments to remove additives from materials during recycling. 


\begin{abstract}
Reusing materials is an attractive option for circular economy and can also reduce emissions of greenhouse gases and pollutants. However, recycling raises questions regarding the potential risks to human health or the environment when hazardous legacy chemical additives of materials are also recycled, instead of the recent and less hazardous additives of virgin materials.

To address this trade-off, this study developed a model to calculate the total external cost of material supply, considering the health and environmental impacts of all industrial steps (virgin material production, incineration, recycling), and the health effects of recycling chemicals present in the material. The model is coupling Material flow analysis, Life-Cycle Analysis, and environmental economics to compare different recycling policies. It is applied for illustrative purposes to soft PVC and DEHP in France. Results show that recycling of materials is in the long-term positive despite the prolongation of the presence of hazardous additives in materials. The time when the recurring environmental benefits of recycling offset the negative impacts on human health of recycling the additives is very sensitive to the health impact of additives. The approach can improve harmonisation between recycling and circular economy policies, and as a framework to confirm the relevance and to size treatments to remove additives from materials during recycling.
\end{abstract}

Keywords :Recycling; Environmental Impacts; Chemicals; External cost; PVC; Material Flow Analysis.

\title{
Table of contents
}

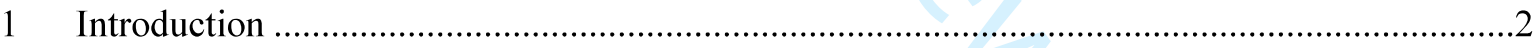

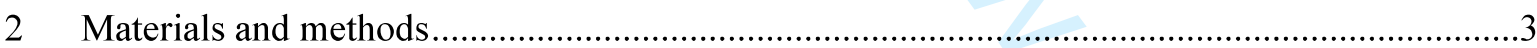

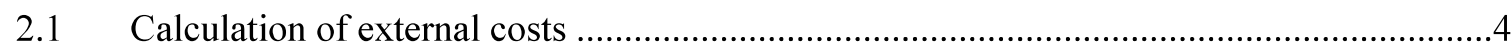

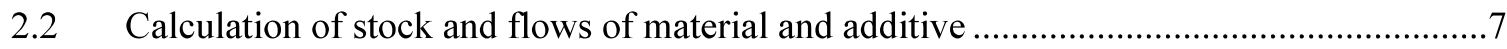

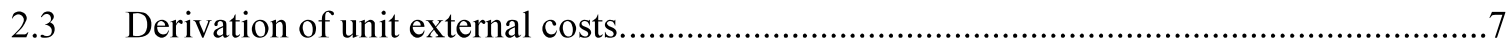

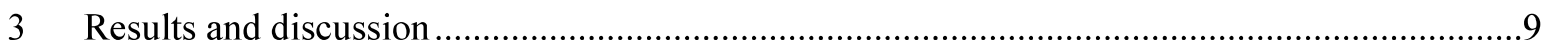

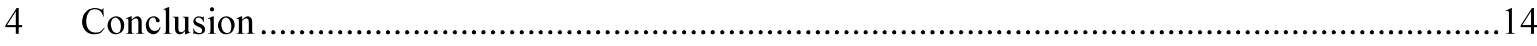

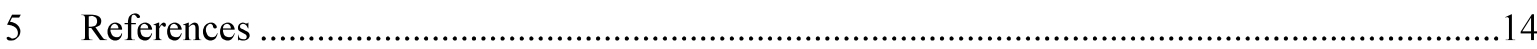




\section{INTRODUCTION}

Reusing materials, particularly plastics, is an attractive option for resource efficiency and energy savings, since it reduces the need for non-renewable oil-based chemistry for plastics. It also avoids emission of pollutants to air and water by production and incineration of virgin materials. A wide range of potentially hazardous chemicals are generally used to confer plastics with required physical and optical properties (Hahladakis et al., 2018). Therefore, recycling can present risks to human health and the environment when hazardous additives of materials are also recycled (Allesch et al., 2014), (Goldberg, 2017), that could otherwise be replaced by more recent and less hazardous chemicals in new virgin material. This calls for benefits/risks assessments of recycling, i.e. the health risks for workers or consumers using recycled materials and articles, and the environmental and energy benefits provided by recycling.

While a vast body of literature studied the GHG or environmental impacts of recycling (for instance (Baitz M., 2004), and more recently for PVC (Hestin et al., 2015; RdC Environnement, 2017), few research attempted a comparison of virgin and recycled PVC materials, also including the risks of the additives, other than the work by (Stichnothe et al., 2013). Despite the importance and complexity of addressing potential leakage of hazardous chemicals during recycling (Hahladakis et al., 2018), especially from food contact materials (Groh K.J. et al., 2019), the focus is generally on $\mathrm{CO}_{2}$ emissions, sometimes also on resource consumption. Air pollutants, water pollutants and health impacts of additives are seldom considered in specific assessments. This work tries to start filling the gap, using Life Cycle Analysis (LCA), but also building on Material/Substance Flow Analysis (MFA) concepts (Bruner et al., 2005). MFA/SFA has been applied to understand the implications of recycling in terms of flows and concentrations (see for instance an application to DEHP in recycled paper (Pivenko et al., 2016), or to brominated flame retardants (Lee et al., 2015)). Some studies have coupled MFA with LCA to investigate the impacts of recycling, but concentrating on a single environmental issue, for instance GHG emissions for paper recycling (SévignéItoiz et al., 2015), or GHG emissions for solid waste management local decisions (Turner et al., 2016). Some authors have worked on coupling SFA/MFA approaches with different sustainability metrics. Monetary metric is recognised as a powerful integration tool (Atkinson G. et al., 2018) and able to improve decision-making regarding risk management of chemicals (Péry et al., 2013), therefore this work couples economic approaches with SFA/MFA and LCA to illustrate health/environmental tradeoffs that policy-makers are facing on recycling policies. This paper uses the concept of external costs, that is traditionally used in LCA to express different impacts in the $€$ common unit (Pizzo M. et al., 2015). (Yuan et al., 2011) adopt a conceptual framework similar to the present paper, to take into account in particular the environmental cost of 
illegal dumping in their cost/benefit study of different policy schemes to manage demolition and construction waste in China.

In terms of regulatory context in the European Union, promoting recycling is one of the key aspects of its circular economy strategy (European Commission, 2015), and recycling targets have been set for municipal and packaging waste of respectively $65 \%$ and $75 \%$ by 2030 . Industry has also taken initiatives to recycle materials, for instance for PVC within the VinylPlus framework (VinylPlus, 2016). To promote demand for recycled plastics, trust in the quality and health and environmental safety of these materials is required (European Commission, 2015) (Baxter et al., 2017). In January 2018, the EC also published its strategy for "Plastics in a circular economy" (European Commission, 2018), confirming the need to address "chemicals of concern" in recycled plastic waste. Regarding the specific case of the phthalate plasticizer DEHP used in soft PVC, after the research project reported here was completed, recycling of soft PVC containing phthalates (DEHP, DiBP, DBP, BBP) at content above $0.1 \%$ has been made impossible because of the end of the deadline to obtain authorisation do to so under the EU REACH Regulation. This regulatory context is an example of difficult trade-offs between recycling and chemicals safety to be made by the EU regulator,

The first objective of this work was to develop a model to calculate the total external cost of material supply, considering the health and environmental impacts of all industrial steps (virgin material production, incineration, recycling), and the health effects of recycling chemicals present in the material, by coupling Material flow analysis, Life-Cycle Analysis, and environmental economics. The second objective was to apply this model to soft PVC and DEHP in France to highlight its use to compare different recycling policies. Given the recent regulatory context under REACH, this makes this application merely illustrative, but it is intended to offer a general framework to improve resolution of future regulatory dilemma on recycling (Wagner S. et al., 2020) by a better representation of trade-offs between the benefits of recycling and its potential negative impacts, and as a tool to confirm the relevance and size treatments to remove additives from materials prior to their recycling.

\section{MATERIALS AND METHODS}

The model calculates the full external costs of supplying a defined market with a material over a specified period, considering the additives, and environmental impacts of production, end-of-life and recycling (on air pollution and GHG emissions). To achieve this, the model also computes the material and substance additives stocks and flows on the market in a continuous time setting. The model is applied for illustration to 
a simplified representation of the French market for soft PVC, in which the end-of-life process is incineration.

This section describes how the model is integrating MFA, LCA, and External Costs, as shown in simplified graphical representation in Figure 1. MFA is providing stocks of the material (PVC) and tis additive (DEHP), and flows of virgin production, incineration and recycling of the material, that are used with LCA to assess emissions of air pollutants and $\mathrm{CO} 2$, with the final step and principal aim of calculating the total external costs of these emissions and of exposure to the additive DEHP.

For simplicity the market is assumed to be isolated, without exports or imports of material. If known, the fraction of virgin or recycled material that is exported can be easily introduced in the MFA.

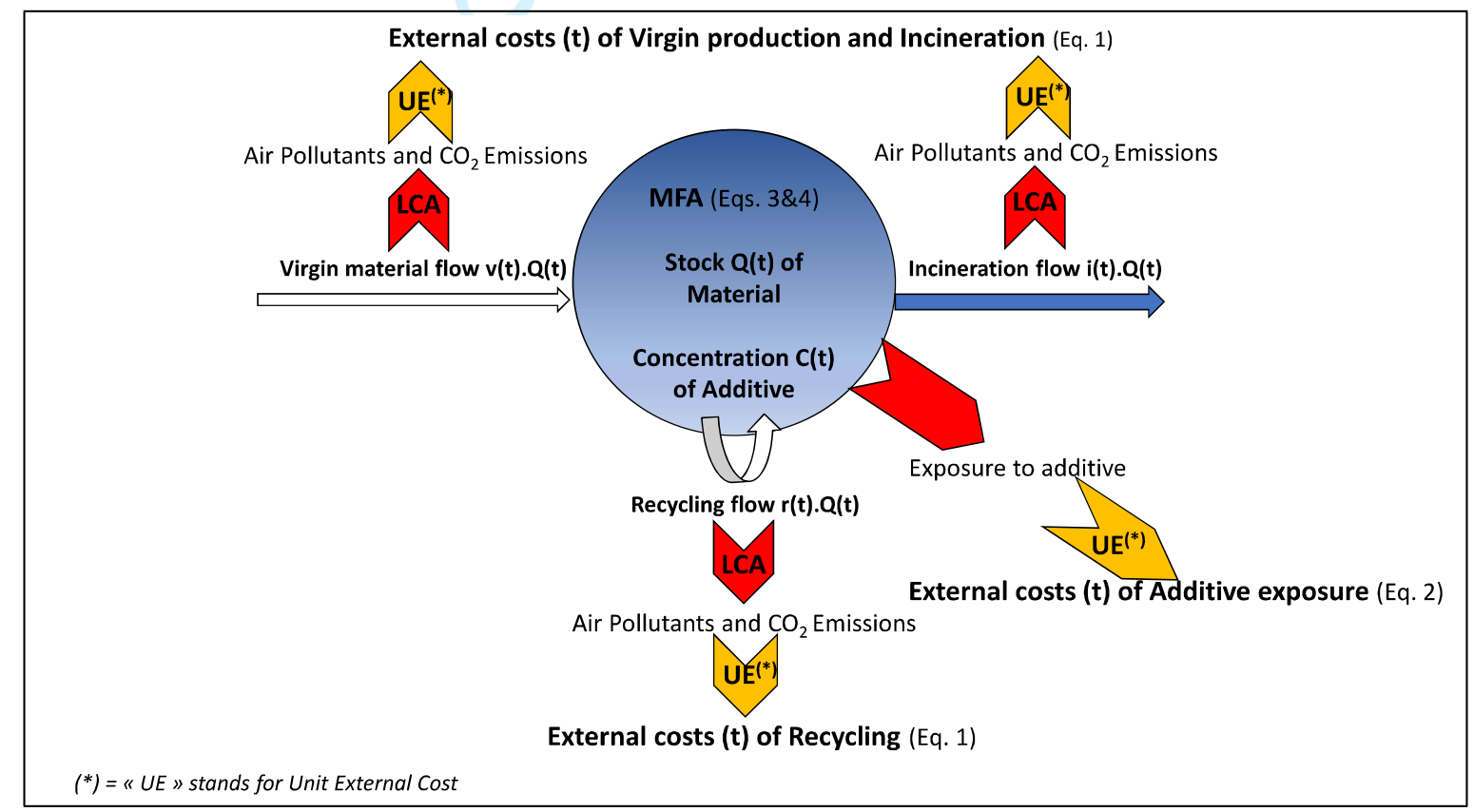

Figure 1 : Graphical representation of the integration between MFA, LCA, and External Costs calculation.

\subsection{CALCULATION OF EXTERNAL COSTS}

The model computes the present value of the total accumulated external cost of supplying the market with the material from time 0 to time $t$, as the sum of : 


\section{1) The external costs of the production, recycling and incineration.}

External costs of production, incineration and recycling are proportional to the amount of material being processed and is computed as :

$$
\begin{aligned}
& \int_{0}^{t} e^{-(d \cdot u)} \cdot(I \cdot i(u) \cdot \mathrm{Q}(\mathrm{u})+\operatorname{R} \cdot r(u) \cdot \mathrm{Q}(\mathrm{u})+P \cdot v(u) \cdot \mathrm{Q}(\mathrm{u})) d u \\
& \int_{0}^{t} e^{-(d \cdot u)} \cdot Q(u)(I \cdot i(u)+R \cdot r(u)+P \cdot v(u)) d u
\end{aligned}
$$

Where $\mathrm{I}, \mathrm{R}$, and $\mathrm{P}$ denote respectively the unitary external costs of incinerating, recycling and producing one unit mass of material, $\mathrm{Q}(\mathrm{t})$ is the stock of material on the market, $i(t), v(t)$ and $r(t)$ respectively denote the incineration, virgin production and recycling rates expressed as a fraction of the stock $\mathrm{Q}(\mathrm{t})^{1}$, and $e^{-d \cdot u}$ is the factor for economic discounting in continuous time, with $d$ the discount rate. Future evolution of incineration is described through the linear ${ }^{2}$ relation $\mathrm{i}=\mathrm{i} * \mathrm{t}+\mathrm{i} 0$ with $\mathrm{i} 0$ initial incineration capacity, where $\mathrm{i}$ can be positive or negative depending on future policies assumed.

Similarly, for virgin production $\mathrm{v}(\mathrm{t})=\mathrm{v} * \mathrm{t}+\mathrm{v} 0$ with $\mathrm{v} 0$ the initial virgin production rate and for recycling $\mathrm{r}(\mathrm{t})=\mathrm{r}^{*} \mathrm{t}+\mathrm{r} 0$ with $\mathrm{r} 0$ the initial recycling rate.

2) The external costs of the use phase are the health impacts of additives, related to their reintroduction on the market by recycling.

At instant $\mathrm{u}$ (between 0 and $\mathrm{t}$ ) a mass $\mathrm{q}(\mathrm{u})=\mathrm{r}(\mathrm{u}) \cdot \mathrm{du} \cdot \mathrm{Q}(\mathrm{u}) \cdot \mathrm{C}(\mathrm{u})$ of additive is introduced on the market through recycling between $u$ and $u+d u$, with $C(u)$ the concentration of the additive in the stock. Its discounted external cost from $u$ (its introduction time) to the time when it is either incinerated or recycled again (and in this latter case introduced again on the market) is proportional to its amount and to the time it remains on the market and is therefore given by :

$$
\int_{\mathrm{u}}^{u+T} e^{-d \cdot s} \cdot \operatorname{ADD} \cdot \mathrm{q}(\mathrm{u}) \cdot d s
$$

\footnotetext{
${ }^{1}$ Usually, incineration, and recycling rates are expressed as a ratio of annual consumption. Working directly with the consumption variable would not allow to represent the stock and flows, but the model also calculate amounts produced, recycled, incinerated, and consumption, and retrieve the usual rates.

2 Other expressions for incineration, recycling and virgin production rates could be adopted, but for the illustrative application to soft PVC, assuming linear trends is adequate.
} 
where ADD denotes the external cost of one unit mass of additive during one unit of time, and $\mathrm{T}$ the mean lifetime of articles on the market (their useful service lifetime plus their hoarding lifetime). We adopt the classical assumption in environmental economics that externalities are proportional the stock of pollution, ADD being the proportionality coefficient.

Different articles have different lifetimes, and for the sake of simplicity the paper assumes that all articles have a common mean lifetime. Equations for several article types can similarly be developed (provided in Supplementary Material, section E).

Therefore the present value of total external cost of all the additive reintroduced on the market through recycling between time 0 and $t$ is given by :

$$
\int_{0}^{t} \int_{\mathrm{u}}^{u+T} e^{-d \cdot s} \cdot \mathrm{ADD} \cdot \mathrm{q}(\mathrm{u}) \cdot d s \cdot d u
$$

After basic calculation and using $\mathrm{q}(\mathrm{u})$ definition above, this leads to :

$$
\left(\frac{A D D}{\mathrm{~d}}\right)\left(1-e^{-d \cdot T}\right) \int_{0}^{t} e^{-d \cdot u} \cdot \mathrm{r}(\mathrm{u}) \mathrm{Q}(\mathrm{u}) \mathrm{C}(\mathrm{u}) \cdot d u^{3}
$$

For simplification, a single additive is considered, however, if several additives are of concern, their external costs can be summed up in the model (see Supplementary Material, section E). Also, for simplicity and because it is relevant for the further application to PVC and DEHP, it is assumed that, comparatively to the hazardous additive considered for recycling, the virgin material is free of hazardous additive.

As illustrated in Figure 1, Eqs.1\&2 explicitly couple economic modelling with Material Flow Analysis and Life-Cycle Analysis : their output (external costs) require as input material and chemicals flows $\mathrm{Q}(\mathrm{t})$ and $\mathrm{C}(\mathrm{t})$ that are the outputs of the Material Flow calculations. Eqs $1 \& 2$ have as parameters R, P, I, and ADD that require Life Cycle Analysis to be estimated. Material Flow calculations and estimation of parameters with LCA are further described respectively in sections 2.2 and 2.3. MFA and External costs calculations are carried out in this study (2.2), whereas for LCA, results from published studies have been used (2.3).

\footnotetext{
${ }^{3}$ In case there is no discounting, $\left(\frac{A D D}{\mathrm{~d}}\right)\left(1-e^{-d . T}\right)$ should be replaced by ADD.T in Eq. 2. Everywhere else in the paper, replace $\mathrm{d}$ by 0 .
} 


\subsection{CALCULATION OF STOCK AND FLOWS OF MATERIAL AND ADDITIVE}

The above calculation of the external costs requires knowledge of $Q(t)$ and $Q(t) . C(t)$,. Basic mathematical integration of classical Material Flow equations for both the material and the additive (provided as Supplementary Material, section A) lead to the following equations in which $\mathrm{Q} 0$ and $\mathrm{C} 0$ respectively denote the initial stock of material and the initial concentration of additive in the stock :

$$
\begin{aligned}
& \mathrm{Q}(\mathrm{t})=Q(0) \cdot e^{\left((\mathrm{v} 0-\mathrm{i} 0) \mathrm{t}+(\mathrm{v}-i) \frac{t^{2}}{2}\right)} \quad(\mathrm{Eq} \cdot 3) \\
& \mathrm{Q}(\mathrm{t}) \cdot \mathrm{C}(\mathrm{t})=Q(0) \cdot \mathrm{C}(0) \cdot e^{-\left(i_{0} \cdot t+i \cdot \frac{t^{2}}{2}\right)}(\mathrm{Eq} \cdot 4)
\end{aligned}
$$

Replacing $\mathrm{Q}(\mathrm{t})$ and $\mathrm{Q}(\mathrm{t}) . \mathrm{C}(\mathrm{t})$ in Eq. 1 \&2 by their expression in Eq. 3\&4 leads to an explicit expressions of the external costs (Supplementary Material, sections B and C).

The mass balance of the additive should in theory consider its degradation during the service life of articles. If $\mathrm{k}$ denotes the constant of a first-order degradation, this would be equivalent to replacing i 0 by $\mathrm{i} 0+\mathrm{k}$ in Eqs. $3 \& 4$. Account could also be taken that there is a time lag (corresponding to the lifetime $\mathrm{T}$ ) between the moment when an article is put on the market and when it is either disposed of or recycled. A sensitivity analysis showed this simplification was for the case of PVC in France a minor source of uncertainty compared to other gaps in knowledge, in the health effects of DEHP for instance. The modelling framework could be easily developed to take account of several types of PVC articles, their recycling patterns, and their different hazardous additives (Supplementary Material, section E).

\subsection{DeRIVATION OF UNIT EXTERNAL COSTS.}

ADD, P, R and I represent respectively the external costs of the additive, and of virgin production, recycling, and incineration processes. They are specific to the material and additives being studied, and we hereafter present their derivation in the case of PVC and DEHP.

$\mathrm{P}, \mathrm{R}$ and $\mathrm{I}$ are derived by multiplying unit emissions of each process (per $\mathrm{kg}$ PVC manufactured or processed) of main pollutants $\left(\mathrm{CO}_{2}, \mathrm{NOx}, \mathrm{SO}_{2}, \mathrm{PM}_{10}, \mathrm{As}, \mathrm{Cd}, \mathrm{Ni}, \mathrm{Pb}\right.$, dioxins), by the unit external costs of the emission of the pollutants by the process (in $€ / \mathrm{kg}$ pollutant emitted). For the additive, the approach is to use the DEHP risk and damage costs assessments that have carried out under EU chemicals regulation. 
The unit external cost of $\mathrm{CO}_{2}$, is retrieved from a European literature review (CavacoPaulo A., 2014), that is consistent with an US review (United States Government, 2016). A higher value of $100 € / t$ was also used for sensitivity analysis. For air pollutants (NOx, $\mathrm{SO}_{2}, \mathrm{PM}_{10}, \mathrm{As}, \mathrm{Cd}, \mathrm{Ni}, \mathrm{Pb}$ and dioxins), specific values of external costs for French industrial point sources computed by (EEA, 2014) are used. External costs of air pollution encompass health impacts, and some effects on the environment (effects of ozone on some crops and of $\mathrm{SO}_{2}$ on materials).

For DEHP, the health impacts related to the reprotoxicity of DEHP have been monetised in (ECHA, 2017) using direct costs to the healthcare systems, and willingness to pay to reduce the probability of diseases related to reprotoxicity. The total costs calculated by ECHA are converted in $€ / \mathrm{kg}$ DEHP placed on the market/year. They vary between a minimum of $0,09 € / \mathrm{kg}$ DEHP.year and a maximum of $4,29 € / \mathrm{kg}$ DEHP.year. To study the impact of the high uncertainty of DEHP external costs, the geometric mean $0,62 € / \mathrm{kg}$ DEHP.year is used as a base case, and the minimum and maximum are used for sensitivity. In accordance with (ECHA, 2017), it is assumed that the alternative plasticizers in virgin soft PVC have a negligible impact on health and the environment compared to DEHP.

Unit external costs are summarized in Table 1.

\begin{tabular}{l|ll} 
Pollutant & $\begin{array}{l}\text { Unit External Cost } \\
\text { Business-as-usual }\end{array}$ & $\begin{array}{l}\text { Unit External Cost } \\
\text { Sensitivity }\end{array}$ \\
\hline $\mathrm{CO}_{2}$ & 0.059 & 0,1 \\
$\mathrm{PM}_{10}$ & 21.2 & 44 \\
$\mathrm{SO}_{2}$ & 15.9 & 16 \\
$\mathrm{NOx}$ & 5.5 & 11 \\
$\mathrm{~Pb}$ & 965 & 437 \\
$\mathrm{Cd}$ & 31 & 136 \\
Dioxins & $27.10^{7}$ & $54.10^{7}$ \\
$\mathrm{DEHP}$ & $0,62 € / \mathrm{kgDEHP} . y e a r$ & $0,09 € / \mathrm{kgDEHP.y} \mathrm{(minimum)}$ \\
& & $4,29 € / \mathrm{kgDEHP.y} \mathrm{(maximum)}$ \\
\cline { 2 - 3 }
\end{tabular}

Table 1: Unit external costs of pollutants in $\epsilon_{2017} / \mathrm{kg}$

Unit emissions of GHG by production, incineration, and recycling are expressed in terms of equivalent $\mathrm{CO}_{2}$. Unit emissions of air pollutants and $\mathrm{GHG}$ are quantified. using 
the published LCA study by (Brown KA et al., 2000) which is to our knowledge the only one covering virgin PVC production, incineration and recycling. For virgin PVC production only, a more recent LCA study is available (Ostermayer et al., 2006), and has been used for sensitivity analysis.

To account for energy consumption during PVC production and recycling, and energy production during PVC incineration, and associated emissions, energy data from (Brown KA et al., 2000) is converted to $\mathrm{CO}_{2}$ emissions using an emission factor of $50 \mathrm{~g}$ $\mathrm{CO}_{2} / \mathrm{MWh}^{4}$. Air pollutants emission factors per $\mathrm{MWh}$ are inferred from the inventory of air pollutant emissions by CITEPA ${ }^{5}$ for 2015 , by dividing air pollutant emissions of French thermal power plants by the energy produced during that year by these power plants (given by RTE) ${ }^{6}$.

Other modelling parameters are the initial stock and additive concentration, the lifetime of articles, and the initial recycling, incineration and virgin production rates.

The initial stock Q0 is unobservable as available statistics only provide amounts annually put on the market, or consumption data. A simple historical stock model described in (Chapon et al., 2017) was used to transform available time series of soft PVC annual production in France in total amounts on market. Articles lifetime T required in Eq. 2 can be deduced from these material stock modeling results, by calculating the average duration for stock renewal, that is 12 years, to be compared with a review of empirical lifetimes in (Chapon et al., 2017), which is 7 years. We use 12 years for the sake of coherence of the modeling assumptions. For the initial DEHP concentration in PVC C0, (ECHA, 2017) suggests a value of $0,08(8 \%)$. For initial incineration, recycling and virgin production rates (i0, $\mathrm{r} 0$, and $\mathrm{v} 0$ ), current incineration and recycling rates in France are $40 \%$ and 20\% respectively (value for all non-mineral materials in 2011) $)^{7}$. The current (2015 data) virgin soft PVC consumption rate for France has been estimated with data from PVC Europe at $218 \mathrm{kt} / \mathrm{y}$.

\section{RESULTS AND DISCUSSION}

Two recycling scenarios of soft PVC in France are modelled: the first one is a continuous increase of recycling compared to a business-as-usual scenario (and

\footnotetext{
${ }^{4}$ Value for the French energy mix in 2015 according to the French Electricity network Authority RTE (https://www.rte-france.com/fr/eco2mix/eco2mix-co2 accessed 25th June 2019).

${ }^{5}$ Centre Interprofessionnel d'Etudes de la Pollution Atmosphérique

${ }^{6}$ Data from https://www.rte-france.com/fr/eco2mix/eco2mix-mix-energetique (accessed 25th June 2019).

7 http://www.statistiques.developpement-durable.gouv.fr/indicateurs-indices/f/1929/1339/taux-recyclagedechets-france.html (accessed 25th June 2019)
} 
therefore parallel decrease of incineration and of virgin production, to have an identical amount on the market in the two scenarios), and in the second one recycling is stopped. The difference in total external costs between the policy and the business-as-usual scenarios is calculated, to quantify the impact of future policy, in terms of environmental and health impacts. Calculations have been carried out by solving explicitly the equations obtained when replacing Eqs $3 \& 4$ in Eqs $1 \& 2$ (see Supplementary Material) and carrying out the numerical application with the data and parameters described in section 2, and scenario-related parameters described hereafter.

Under the business-as-usual scenario, recycling, incineration, and virgin production rates ( $\mathrm{r}, \mathrm{v}$ and $\mathrm{i}$ ) are calibrated so that the mean annual growth rate of the PVC market over the period is 2,5\% (past trend from PVC Europe data) and that the annual recycling rate (initially of $40 \%^{8}$ ) increases by $2 \%$ each year (illustrative assumption). For that purpose, amounts of annual virgin, incinerated and recycled of PVC are computed (see Supplementary Material, Section D), and annual consumption is further calculated as production + recycling - incineration).

We first assess a future increase in recycling by computing the difference in total external costs between an "increased recycling" scenario and the business-as-usual.

The"increased recycling" scenario has the same initial conditions and parameters as the business-as-usual, but a progressive increase in recycling : $r(t)=r 0+r . t$ with $r>r$ in the business-as-usual scenario. To keep the stock, the growth rate $v(t)-i(t)$, and therefore market demand identical between this scenario and the business-as-usual, this increase is counterbalanced by a parallel reduction in incineration and virgin production.

The "increased recycling" scenario remains less favorable (higher external costs) than the business-as-usual over the study period, because of the additional negative health impacts of exposure of consumers to DEHP through increased recycling (Figure 2). However, on the longer term, the balance turns in favor of the "increased recycling" scenario (continuation of downward trend after 2035), since DEHP concentrations decrease, while the other recurring environmental benefits of recycling remain constant. The inverted U-shape of the curve illustrates that in the shorter term, negative impacts of increased relooping of DEHP in the economy dominate, whereas in the longer-term, the benefits of avoided process-related emissions of $\mathrm{CO}_{2}$ and pollutants dominate and increase with time.

\footnotetext{
${ }^{8}$ See note 7 page 9 for the source used regarding this value of $40 \%$
} 


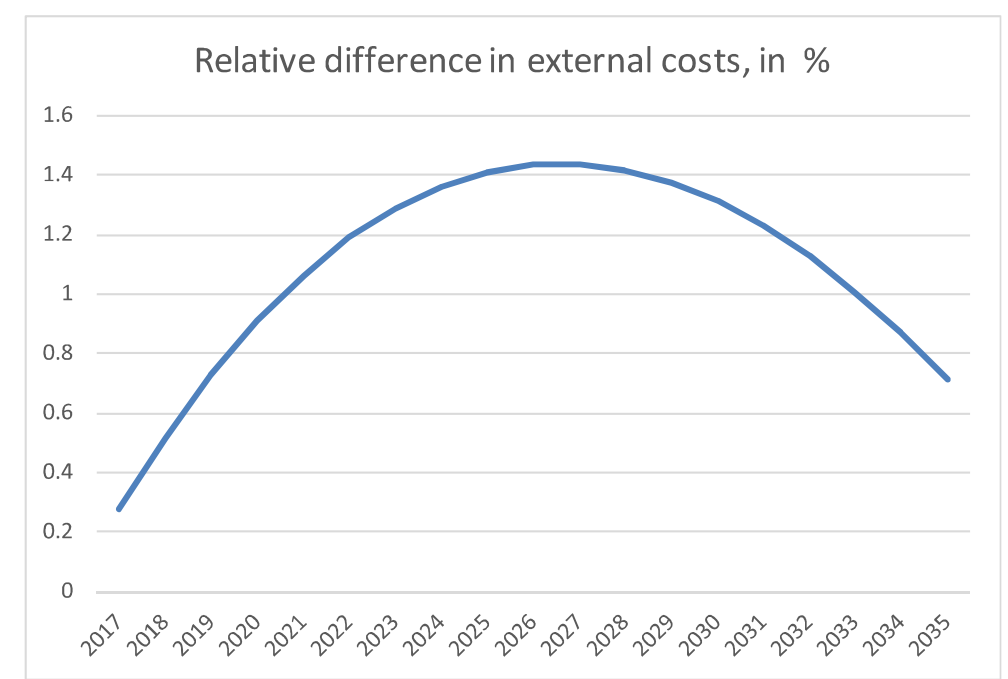

Figure 2: Relative difference in total external costs (\%) between the "business-asusual" and the "increased recycling" scenarios

In the above results, the time to reach neutral environmental impacts ( $0 \%$ difference) when increasing recycling is around 20 years. Sensitivity scenarios using the "sensitivity values" in Table 1 above, show that this time is extremely sensitive to key parameters (DEHP unit external cost) and relatively insensitive to others (unit external costs of pollutants, and discount rate). For the "Maximum Value" and "Geometric Mean*2" sensitivity values of DEHP, the time it would take to compensate negative impacts of DEHP is very long, and far beyond the reasonable limit to push into the future the modelling underlying assumptions about future technology performance and their use.

Sensitivity to DEHP external cost (Figure 3) comes from the high uncertainty regarding the actual extent of its health impacts, especially the fraction of all observed cases of infertility and of malformations of male genitals attributable to this chemical (ECHA, 2017). 


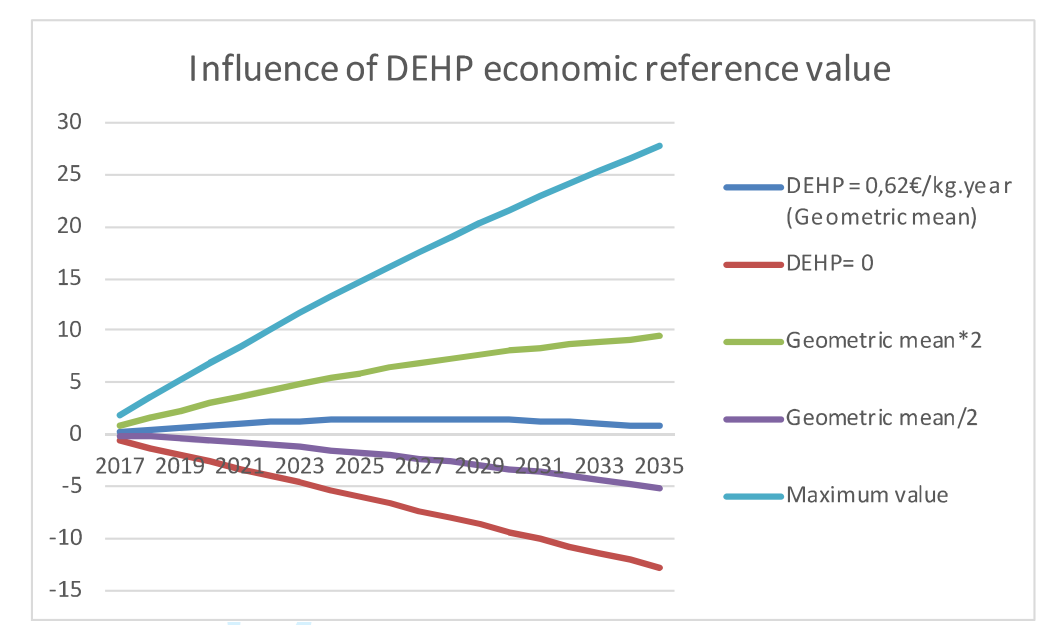

Figure 3 : Influence of DEHP economic reference value on the relative difference of total external costs between the reference and "increased recycling" scenarios

To illustrate the consequences of stopping recycling, while ensuring the same amount of PVC articles is available to consumers as in the business-as-usual, we define a "no recycling" scenario in which virgin production and incineration are increased to compensate for the loss of recycling. It is found that on the long term (later than 2035), additional virgin production and incineration will more than offset the positive health impacts of stopping recycling of DEHP (Figure 4).

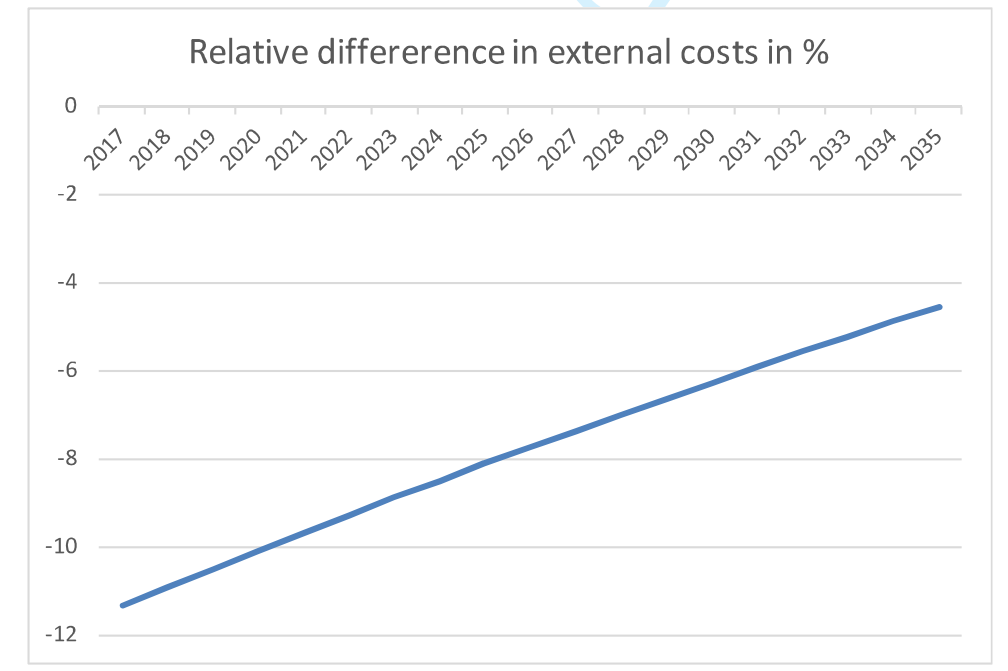

Figure 4 : Relative difference in total external costs (\%) between the "business-asusual" and the "stopping recycling" scenarios 
Again, results depend dramatically on the unit external cost of DEHP as shown in Figure 5. Estimating the exact future offset date would require to push the assumptions into the future far beyond what can be meaningfully assumed about future technology performance and their use.

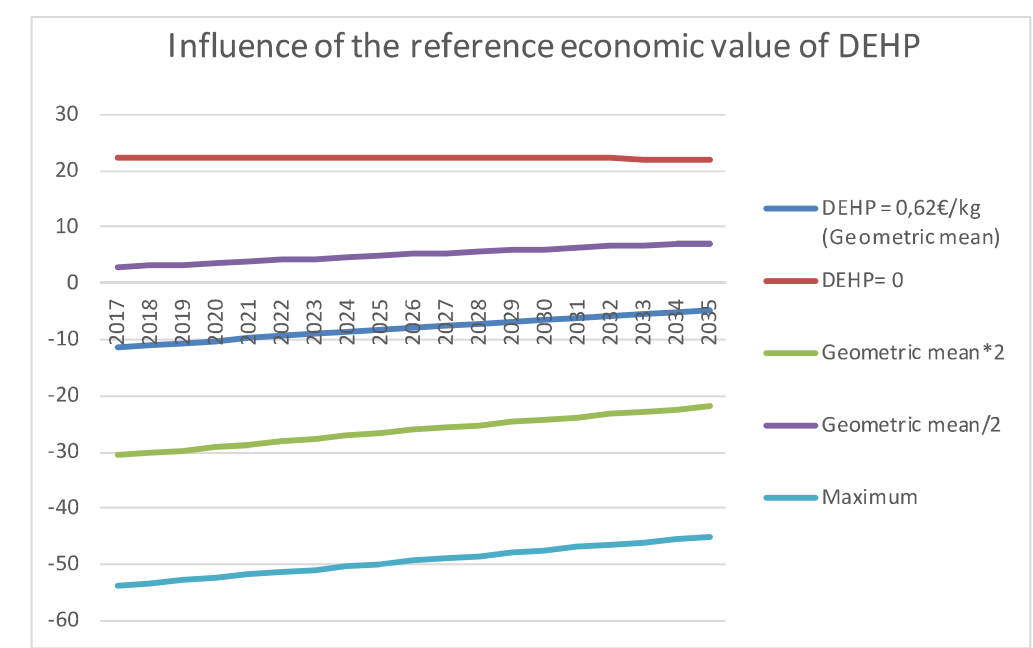

Figure 5 : Influence of DEHP economic reference value on the relative difference of total external costs between the reference and "stopping recycling" scenarios

Both scenarios highlight that the negative impact of recycling hazardous additives is only transient, but can become unacceptable to society when these negative impacts delay considerably the occurrence of the overall benefits of recycling. Depending on their magnitude, such delay and negative health impacts can justify the investment in treatment for the removal or the transformation of the additives before recycling, that is currently the focus of research and industrial developments (Wagner S. et al., 2020). In this context, the present paper offers a framework to assess the relevance and optimal timing of such investments. However, in this case study, the large uncertainties regarding the health impacts of DEHP, and of other chemicals, make any conclusion difficult. This could limit the practical applicability of the model in terms of chemicals coverage, but conversely can help identify where more knowledge is required for policymaking. Applying modelling to specific articles instead of whole market could also limit the part of uncertainties that relate to exposure. 


\section{CONCLUSION}

This study coupled physical (MFA), environmental (LCA) and economic (External costs) approaches, to assess the trade-offs between environmental benefits of recycling and its possible negative health impacts related to hazardous legacy additives, for the illustrative case of PVC and DEHP. Results highlight the contrast between short-time and long-term conclusions: after possible short-term negative impacts of additives can dominate the balance, on the long term, increasing recycling of materials is positive despite the prolongation of the presence of hazardous additives on the market. The model can estimate the time when the recurring environmental benefits of recycling offset the negative impacts of recycling the additives. However this requires reasonable knowledge of health impacts of the additives, which has been shown to remain to limited to be able to draw conclusions, in the illustrative case of DEHP. Progress in knowledge about health impacts of chemicals is therefore key in better decisions regarding recycling policies taking into account the balance with chemicals safety.

The recent regulatory context under REACH makes the application to DEHP in PVC merely illustrative, but the approach can improve the resolution of future regulatory dilemma on recycling (Wagner S. et al., 2020) by a better representation of trade-offs between the benefits of recycling and its potential negative impacts, and as a framework to confirm the relevance and to size treatments to remove additives from materials prior to their recycling.

The approach presented here can also quantify and help realize the external costs that materials use put on our society, and study analytically the conditions for an environmentally sustainable circular economy. Importance of materials for sustainability is appearing critical now more than ever before (OECD, 2019). The present work offers progress towards being able to measure the sustainability of our materials consumption and compare it with environmental and health long-term objectives. Alongside the development of such modelling, there is therefore a need for thresholds and targets for long term acceptable pollution and its external costs.

This work was supported by the French Ministry for a Solidary Ecological Transition under grant INERIS DRC 181 - 53 / 2017. 


\section{REFERENCES}

Allesch, A., Bruner P.H. (2014) Assessment methods for solid waste management: a literature review. Waste Manag. Res. 32, 461-473. https://doi.org/10.1177/0734242X14535653

Atkinson G., Braathen N.A., Groom B., Mourato S. (2018) Cost-Benefit Analysis and the Environment: Further Developments and Policy Use, OECD Publishing, Paris, https://doi.org/10.1787/9789264085169-en.

Baxter W., Aurisicchio M. (2017) Contaminated Interaction : Another Barrier to Circular Material Flows. J. Ind. Ecol. 21, 3, 507-516. https://doi.org/10.1111/jiec.12612

Brown K.A., Holland M.R., Boyd R.A., Thresh S., Jones H., Ogilvie S.M. (2000) Economic Evaluation of PVC Waste Management, AEA report produced for European Commission Environment Directorate

http://ec.europa.eu/environment/waste/studies/pvc/economic eval.pdf (accessed 25 June 2019)

Bruner P. H., Rechberger H. (2005) Practical Handbook of Material Flow Analysis, Lewis Publishers

Baitz M., Kreissig J., Byrne E. (2004) Life Cycle Assessment of PVC and of principal competing materials, Report Commissioned by the European Commission.

http://ec.europa.eu/environment/waste/studies/pdf/pvc-final_report lca.pdf (accessed 25 June 2019)

Cavaco-Paulo A. (2014) EU FP7 NANOFOL Project Final Report. https://cordis.europa.eu/docs/results/228827/final1-wp7-d7-5-finalpublicreport-m48290114.pdf (accessed 25 June 2019)

Chapon V. and Brignon J.M. (2017) Estimation des émissions de DEHP sur le bassin de la Seine. INERIS report DRC-17-167214-10084A , Programme PIREN-Seine, https://www.pirenseine.fr/sites/default/files/PIREN documents/phase 7/rapports annuels/2016/a1bt2 Ch apon-Brignon_PIREN 2017.pdf (accessed 25 June 2019) 
ECHA (2017) Committee for Risk Assessment (RAC) \& Committee for Socioeconomic Analysis (SEAC), Background document to the Opinion on the Annex XV dossier proposing restrictions on four phthalates (DEHP, BBP, DBP, DIBP). https://echa.europa.eu/documents/10162/e603ff27-25ae-2c6d-8210-a65e49046e19 (accessed 25 June 2019)

EEA (2014) Costs of air pollution from European industrial facilities 2008-2012 : an updated assessment. EEA report 20/2014. https://www.eea.europa.eu/publications/costs-of-air-pollution-2008-2012 (accessed 25 June 2019)

European Commission (2015) Communication from the commission to the European parliament, the council, the European economic and social committee and the committee of the regions : Closing the loop - An EU action plan for the Circular Economy. $\operatorname{COM}(2015) \quad 614$ final, https://eur-lex.europa.eu/legalcontent/EL/TXT/PDF/?uri=CELEX:52015DC0614\&from=EN (accessed 25 June 2019)

European Commission (2018) Communication from the Commission to the European Parliament, the Council, the European economic and social committee and the Committee of the regions, A European Strategy for Plastics in a Circular Economy, $\operatorname{COM}(2018) 28$ final, https://eur-lex.europa.eu/resource.html?uri=cellar:2df5d1d2-fac711e7-b8f5-01aa75ed71a1.0001.02/DOC 1\&format=PDF

Goldberg, T. (2017) What about the Circularity of Hazardous Materials? J. Ind. Ecol. 21, 491-493. https://doi.org/10.1111/jiec.12585

Groh K.J., Backhaus T., Carney-Almroth B., Geueke B., Inostroza P.A., Lennquist A., Leslie HA, Maffini M., Slungef D., Trasande L., Warhurst A.M., , Muncke J., 2019, Overview of known plastic packaging-associated chemicals and their hazards, Sci. Tot. Env. 651, 3253-3268

Hahladakis J. N., Velin C.A, Weber R., Iacovidou E., Purnell P. (2018) An overview of chemical additives present in plastics: Migration, release, fate and environmental impact during their use, disposal and recycling, J. Haz. Mat. 344, 179-199.

https://doi.org/10.1016/j.jhazmat.2017.10.014

Hestin M., Faninger T., Milios L. (2015) "Increased EU Plastics Recycling Targets: Environmental, Economic and Social Impact Assessment", Final Report by 
BiobyDeloitte for Plastic Recyclers Europe. http://plasticsrecyclers.eu/sites/default/files/BIO_Deloitte_PRE_Plastics\%20Recycling \%20Impact_Assesment_Final\%20Report.pdf (accessed 25 June 2019)

Lee S., Yang Y-C., Him J-G., Park J-E., Kang Y_Y., Kim W-I., Shin S-K. (2015) Static and dynamic flow analysis of PBDEs in plastics from used and end-of-life TVs and computer monitors by life cycle in Korea, Sci. Tot. Env. 506-507, 76-85. https://doi.org/10.1016/j.scitotenv.2014.10.116

OECD (2019) Global Material Resources Outlook to 2060: Economic drivers and Environmental Consequences, OECD Publishing, Paris, https://doi/org/10.1787/9789264307452-en

Ostermayer A., Giegrich J. (2006) Eco-profiles of the European Plastics Industry Polyvinylchloride (PVC) (suspension polymerisation), report for The European Council of Vinyl Manufacturers (ECVM) \& PlasticsEurope

Péry A., Schüürmann G., Ciffroy P., Fauste M., Backhause T., Aicherf L., Mombelli E., Tebbya C., Croning MTD, Tissot S., Andres S., Brignon J.M., Freweri L., Georgiou S., Mattask K., Vergnaud J.C., Peijnenburg W., Capri E., Marchis A., Wilks M.F. (2013) Perspectives for integrating human and environmental risk assessment and synergies with socio-economic analysis., Sci Total Environ. Jul 1;456-457. https://doi.org/10.1016/j.scitotenv.2013.03.099

Pivenko K., Laner D., Astrup T.F (2016) Material Cycles and Chemicals: Dynamic Material Flow Analysis of Contaminants in Paper Recycling, Environ. Sci. Technol., 50, 12302-12311. https://doi.org/10.1021/acs.est.6b01791

Pizzo M., Weidema B., Brandao M., Osset P. (2015) Monetary valuation in Life Cycle Assessment: a review, J. Clean. Prod. 86, 170-179, http://dx.doi.org/10.1016/j.jclepro.2014.08.007

RdC Environnement (2017) Évaluation environnementale du recyclage en France selon la méthodologie de l'analyse de cycle de vie, report for FEDEREC and ADEME. https://presse.ademe.fr/wp-content/uploads/2017/05/FEDEREC_ACV-du-Recyclageen-France-VF.pdf (accessed 25 June 2019) 
Sévigné-Itoiz E., Gasol C.M., Rieradevall J., Gabarell X. (2015) Methodology of supporting decision-making of waste management with material flow analysis (MFA) and consequential life cycle assessment (CLCA): case study of waste paper recycling, J. Clean. Prod. 105, 253-262 https://doi.org/10.1016/j.jclepro.2014.07.026

Stichnothe, H., Azapagic. A. (2013) Life Cycle Assessment of recycling PVC window frames, Resources, Conservation and Recycling, 71, 40-47. https://doi.org/10.1016/j.resconrec.2012.12.005

Turner D., Williams I.D., Kemp S. (2016) Combined material flow analysis and life cycle assessment as a support tool for solid waste management decision making, J. Clean. Prod. 129 (2016) 234-248 https://doi.org/10.1016/j.jclepro.2016.04.077

United States Government, Interagency Working Group on Social Cost of Greenhouse Gases (2016) Technical Support Document: Technical Update of the Social Cost of Carbon for Regulatory Impact Analysis Under Executive Order 12866 https://www.epa.gov/sites/production/files/201612/documents/sc_co2_tsd_august_2016.pdf (accessed 25 June 2019)

VinylPlus (2016) Progress Report 2016 reporting on 2015 activities, https://vinylplus.eu/uploads/160826_VINYPLUS_2016_WEB_PS_Singlepage_version. pdf (accessed 25 June 2019)

Wagner S., Schlummer M., 2020, Legacy additives in a circular economy of plastics: Current dilemma, policy analysis, and emerging countermeasures, Resources, Conservation \& Recycling 158104800 